\title{
Avaliação in vitro da atividade antimicrobiana do ozônio gasoso e do óleo ozonizado
}

DOI: 10.47224/revistamaster.v6i11.163

\author{
Kalyandra Gomes \\ Ecila Vieira Cunha \\ Vitoria Lannes Galdino \\ Aline Fernandes Hipolito
}

e-mail: alinehipolito_81@hotmail.com

\section{Resumo}

O gás ozônio foi descoberto no século XIX por seu odor característico gerado quando o oxigênio era submetido a uma descarga elétrica e, desde então, vem sendo estudado e testado de diversas formas. No momento presente, vários estudos indicam que a ozonioterapia tem demonstrado ótimos resultados no tratamento de variadas patologias, além da utilização do ozônio também ser um método eficaz para esterilização de espaços/objetos médicos e odontológicos, uma vez que a geração do gás é de baixo custo quando obtido o equipamento. Diante desse cenário, o presente trabalho tem por objetivo avaliar a capacidade de ação do gás de ozônio e do óleo ozonizado frente a patógenos importantes: Staphylococcus aureus, Escherichia coli. e Staphylococcus aureus resistente a meticilina, por meio de teste in vitro feito em laboratório do Centro Universitário IMEPAC. Os resultados foram positivos em relação ao gás, evidenciando uma ótima alternativa como sanitizante de baixo custo e sem formação de produtos tóxicos. Já com relação ao óleo ozonizado a falta de parâmetros precisos de comparação, os possíveis problemas de interação do mesmo com o papel filtro, ou mesmo sua alta concentração, podem ter sido indicadores que geraram resultados menos expressivos. Todavia, mesmo com algumas restrições, foi confirmada a capacidade do gás e do óleo ozonizado de conter e combater o crescimento de microrganismos.

Palavras-chave: Ozonioterapia, gás ozônio, ação antimicrobiana, óleo ozonizado.

\begin{abstract}
Ozone gas was discovered in the $19^{\text {th }}$ century, by its characteristic odor when oxygen was subjected to an electrical discharge and, since then, it has been studied and tested in several ways. At the present time, several studies indicate that ozone therapy has shown excellent results in the treatment of several pathologies, besides the use of ozone also being an effective method for sterilizing medical and dental spaces and objects, since the gas generation is low cost when obtained the equipment. Given this scenario, the present work aims to evaluate the ability of ozone gas and ozonized oil to act against important pathogens: Staphylococcus aureus, Escherichia coli. and Multiple-resistant Staphylococcus aureus, through in vitro test done in the laboratory of the Centro Universitário IMEPAC. The results were positive about the gas, showing a great alternative as a low-cost sanitizer without the formation of toxic products. In relation to ozonized oil, the lack of precise parameters of comparison, the possible problems of its interaction with the filter paper, or even its high concentration, may have generated less expressive results. However, even with some restrictions, the ability of ozonized gas and oil to contain and combat the growth of microorganisms has been confirmed.
\end{abstract}

Keywords: $\quad$ Ozone therapy, ozone gas, antimicrobial action, ozonized oil.

\section{INTRODUÇÃO}

A necessidade do controle de infecções e o desenvolvimento de microrganismos multirresistentes, vêm intensificando a busca por métodos de esterilização seguros e eficazes. 0 ozônio é uma forma alotrópica do oxigênio, considerado um poderoso agente oxidante. Acredita-se que ele possa oxidar aminoácidos e destruir proteínas presentes na membrana citoplasmática dos microrganismos e, com isso, apresentar excelentes propriedades antimicrobianas; além de promover a inibição do 
crescimento de fungos e interromper o ciclo de replicação viral, alterando o contato do vírus com a célula por meio da peroxidação (GURLEY, 1985).

Por possuir propriedades antimicrobianas, o ozônio já é utilizado como alternativa no processo de descontaminação da água, alimentos, equipamentos e instrumentos (RICE et al., 1981). Segundo Sechi e seus colaboradores (2001), o ozônio não contamina a atmosfera e nenhuma resistência bacteriana a essa substância foi relatada até o momento.

Além dessa função no processo de descontaminação, o ozônio também tem sido utilizado, desde o século XIX, como terapia para o tratamento de diversas patologias (NOGALES et al., 2008). Segundo Bocci e seus colaboradores (2005), a ozonioterapia é a técnica que utiliza o ozônio como agente terapêutico para diversas doenças, atualmente, é uma prática aprovada em vários países, porém, ainda não muito difundida e bem aceita no Brasil. Como terapia utilizada em humanos, sua aplicação pode ser realizada por via subcutânea, intramuscular, intradiscal, intracavitária (espaços peritonial e pleural), intravaginal, intrauretral, sublingual, retal e autohemoterapia ozonizada.

Apesar de não ter uso comum, como descrito, essa terapia tem sido reconhecida como válida e eficaz, o que tem feito com que estudiosos se interessem e sejam realizadas cada vez mais pesquisas com intuito de validar a utilização desse gás para auxiliar em tratamentos de feridas extensas, infecções fúngicas, bacterianas e virais, lesões isquêmicas e várias outras afecções (GIMENES, 2008).

Inclusive, sua prática foi recentemente regulamentada pelo Conselho Federal de Farmácia (CFF), que, por meio da resolução no 685/2020, regulamenta a atuação prática do farmacêutico na utilização da ozonioterapia clínica e estética. A partir dessa resolução, ficou especificado que:

O farmacêutico realize a consulta e anamnese farmacêutica, para avaliar sinais e sintomas, identificar as necessidades do paciente e realizar a prescrição farmacêutica em ozonioterapia. O profissional também poderá, entre outras atividades, escalonar as doses de ozônio medicinal a serem utilizadas e a via adequada de acordo com a avaliação das necessidades do paciente e aplicar o ozônio medicinal de maneira isolada ou em combinação, para uso clínico ou estético (BRASIL, 2020, s/p).

Tal resolução foi considerada de grande importância para os profissionais, mas também para a população, visto que a ozonioterapia é considerada um tratamento com valor acessível, bem como, por aumentar a oxigenação tecidual e, consequentemente, melhorar o metabolismo, apresentando ainda ação positiva em doenças infecciosas agudas e, também, em quadros crônicos, como queimaduras, úlceras diabetogênicas, dentre outras (LEÓN et al., 1998).

Na aplicação em materiais odontológicos, seu uso é indicado também na higienização dos equipamentos, inibindo a formação de "biofilme" bacteriano. Adicionalmente, Pereira e seus colaboradores (2005), apontaram que o ozônio é um potente inibidor do crescimento bacteriano in-vitro. Diaz e estudiosos (1995), corroboram com tais ideias, destacando que o ozônio é utilizado há mais de 80 anos para tratamento de água potável, além de sua evidente eficiência no tratamento da água de uso hospitalar e em unidades de equipamentos odontológicos.

Somada às funções apresentadas anteriormente, nos últimos meses, visualizou-se a possibilidade do uso do gás ozônio frente ao coronavírus (SARS-CoV2), denominado de "coronavírus 2019" (COVID-19), que se apresenta a nível mundial, se tornando uma ameaça para a população de um modo geral e para os profissionais de saúde, em que o mesmo pode ser utilizado como adjuvante no tratamento antiviral (FARIAS et al., 2020). Além disso, o gás pode se apresentar como uma alternativa para a falta de equipamentos de proteção individual - EPI's nos hospitais que, durante a pandemia atual, pela sua capacidade de desinfecção, pode ser utilizado para esterilizar e reutilizar alguns materiais de proteção, bem como outros instrumentos e o próprio ambiente hospitalar (DENNIS, 2020).

A aplicação do ozônio tópico é ideal para os casos de problemas cutâneos, podendo ser feita por meio do óleo ozonizado, que desempenha efeito antisséptico e estimulante, os quais atuam nas fases de proliferação e remodelação da cicatrização de feridas, além de reduzir sintomas como inchaço, vermelhidão e dor local (LUONGO, 2003). 
Sendo assim, levando em conta a alta capacidade de ação do ozônio frente aos microrganismos, a existência de inúmeros patógenos associados a diversas infecções importantes e considerando ainda a existência de poucos estudos referentes ao assunto, esse trabalho tem como objetivo analisar o efeito do gás ozônio e do óleo ozonizado quando aplicado sobre três bactérias causadoras de importantes patologias dentro e fora do ambiente hospitalar - Staphylococcus aureus, Escherichia coli e Staphylococcus aureus resistente a meticilina; bem como comparar a capacidade de atuação entre os dois métodos de aplicação.

\section{REFERENCIAL TEÓRICO}

O ozônio é uma molécula termodinamicamente instável, volátil e parcialmente solúvel em água, reconhecido por seu alto poder oxidante. Azuma e seus colaboradores (2014), afirmam que tal molécula é formada por 3 átomos de oxigênio com peso molecular de $47,98 \mathrm{~g} / \mathrm{mol}$ e sua estabilidade depende de condições de temperatura e pressão, podendo ser rapidamente convertido em $\mathrm{O}_{2}$. $\mathrm{O}$ mesmo possui um forte odor característico e irritante, facilmente identificado em pequenas concentrações (0,01 a 0,05 mg/L) (RICE et al., 1981).

Estudos recentes vêm demostrando que o ozônio medicinal tem propriedades antimicrobianas de amplo espectro. E, nesse sentido, diversas referências científicas indicam a efetividade do ozônio contra microrganismos - bactérias, fungos e vírus. Isso porque ele possui capacidade de se difundir e penetrar nos tecidos, bem como se dissolver no plasma sanguíneo e nos fluidos extracelulares, entretanto, o ozônio não permanece estável nesses meios líquidos, já que é um potente oxidante e acaba reagindo imediatamente com moléculas presentes nesses meios, chamadas de antioxidantes, como proteínas, carboidratos e ácidos poli-insaturados (BOCCl et al., 2005).

O autor supracitado afirma ainda que a reação inicial ocorre quando a molécula de ozônio é oxidada pelo ácido ascórbico, grupos de proteínas sulfidrila e glicoproteínas. Esta reação gera espécies reativas de oxigênio (ROS), que são neutralizadas rapidamente pelo sistema antioxidante.

A segunda reação é, portanto, a de degradação oxidativa dos lipídeos, a qual, no plasma hidrofílico, uma molécula de olefina (hidrocarbonetos que possuem cadeia aberta e ligações duplas) e uma molécula de ozônio geram duas moléculas de aldeídos e uma molécula de peróxido de hidrogênio. Essas duas reações, completas em segundos, geram peróxidos de hidrogênio e uma variedade de aldeídos que são produtos lipídicos oxidantes (LOPs) (BOCCl et al., 2005).

Assim, a ação do ozônio é designada pela proliferação de muitas outras substâncias oxidantes que podem concorrer ou complementar a ação do ozônio para destruir locais críticos dentro da célula ou geralmente para oxidar protoplasma (FISHER et al., 2000).

A ação antimicrobiana direta contra bactérias, vírus e fungos que o ozônio exerce é facilitada por esses microrganismos não possuírem um sistema de tamponamento antioxidante, portanto, o estresse causado pelo ozônio acaba tornando-os frágeis. Já a ação microbicida indireta do ozônio é resultante das mudanças metabólicas que este provoca (PEREIRA et al 2005; WENTWORTH et.al, 2002).

Os peróxidos resultantes da reação do gás ozônio com dois carbonos insaturados, presente em ácidos graxos, também são uma causa importante de toxicidade, e atuam também nos grupos sulfidrilas de certas enzimas, resultando na interrupção da atividade enzimática celular normal. No caso das bactérias, a morte é rápida e é frequentemente atribuída a mudanças na permeabilidade celular, seguida pela lise celular. Entretanto a lise, provavelmente não é por um mecanismo primário de inativação, mas como consequência de uma alta concentração de oxidante. Como o ozônio tem sua meia vida curta, ele acaba por formar ozonídeos que são definidos como espécies reativas de oxigênio, ou mesmo dos subprodutos da oxidação lipídica (OLIVEIRA, 2008).

Portanto, a facilidade prática de uso e a eficiência do ozônio como virucida o tornam uma alternativa muito lógica para a desinfecção de ambientes e equipamentos de proteção, como máscaras faciais N95, luvas, macacões impermeáveis e outros itens. O fato de o gás ozônio ser um virucida seco torna a opção particularmente eficaz para materiais porosos, fibrosos ou texturizados. Atingindo as fendas que os desinfetantes ou a esterilização ultravioleta não conseguem, sendo desta forma uma excelente alternativa para reverter à falta de EPI dos hospitais (DENNIS, 2020). 
Tais aspectos fazem do ozônio uma ferramenta importante na atual pandemia, uma vez que o mesmo age para destruir as partículas virais através da oxidação e, considerando que o SARS-CoV-2 (responsável pelo COVID-19), que é um vírus envelopado, membro da família Coronaviridae, seja particularmente suscetível à destruição por ozônio, visto que, no caso de vírus envelopados, o ozônio oxida prontamente o envelope viral, alterando sua estrutura ou destruindo-o e tornando-o inativo (FARIAS et al., 2020).

Tal autor afirma ainda que, referente ao COVID-19, existe a possibilidade de utilização da ozonioterapia como complemento no tratamento da doença, visto que a ação imunológica do ozônio está dirigida fundamentalmente sobre os monócitos e linfócitos $T$, os quais uma vez induzidos, liberam pequenas quantidades de citocinas, tais como: interferongamma (IFN-y) fator de necrose tumoral (TNF) e interleucina-2 (IL-2). Assim, tanto a atividade moduladora da inflamação como a oxigenação nos tecidos melhora e, em combinação ainda com a indução da ativação de anticorpos e citocinas, ajudam a estruturar a resposta imunológica de combate a diversos tipos virais (FARIAS et al., 2020).

Ainda analisando o cenário hospitalar atual, quando observamos algumas bactérias mais comumente encontradas nesses ambientes, percebemos que de acordo com Santos et al., (2007), a Staphylococcus aureus é considerada uma das principais bactérias nos quadros de infecções hospitalares e comunitárias, causando doenças infecciosas que variam de uma acne e furúnculo, até casos mais graves, como pneumonia, meningite, endocardite, síndrome do choque tóxico e septicemia, entre outras. Trata-se de uma bactéria com grande capacidade de adaptação e resistência a antibióticos.

\section{A presença da MRSA (Methicillin Resistant} Staphylococcus aureus/S.aureus resistente a meticilina) é também frequentemente comum. Nesse caso, trata-se de cepas evoluídas, extremamente insensíveis e resistente a diferentes tipos de antimicrobianos, o que a torna uma ameaça para a saúde pública, visto que amplia os casos de mortalidade, morbidade e gera altos custos para seu tratamento em busca de combatê-la (FERRACIOLI JUNIOR et. al, 2019).

Já a Escherichia coli (E. coli) se trata de bactéria gram-negativa, que se encontra no intestino de seres humanos saudáveis, portanto, algumas cepas se desenvolvem causando infecções no aparelho digestivo, urinário e/ou em muitas outras partes do corpo. Trata-se de uma bactéria que pode ser transmitida com facilidade para outras pessoas e, em muitos casos, recomenda-se evitar o uso de antibióticos para seu tratamento, como é o caso de diarreias. No entanto, ao evoluir para fora do intestino, o uso de antibióticos passa a ser indicado. É uma bactéria bastante comum, que está relacionada à falta de higiene e, portanto, atinge parcela considerável da população, o que despende gastos da saúde pública para tratamento (SOUZA et al., 2016a).

O gás ozônio, conforme alguns estudos ressaltam, pode ser tóxico ao organismo, principalmente quando inalado. Entretanto, Elvis (2011) adverte que diversas pesquisas evidenciaram benefícios quanto ao uso terapêutico do $\mathrm{O}_{3}$. Na medicina, a ozonioterapia consiste na aplicação de mistura $\mathrm{O}_{2} / \mathrm{O}_{3}$, que possui diversos efeitos no sistema imune como modulação da fagocitose dos macrófagos, inativação de microrganismos, ação antiinflamatória, entre diversas outras.

Com relação a um possível aumento do estresse oxidativo provocado pelo ozônio, foi descoberto que, na verdade, $\mathrm{O} \mathrm{O}_{3}$ aumenta a atividade de enzimas antioxidantes, incluindo glutationaperoxidase, superóxido dismutase (SOD) e catalase, preparando o organismo para enfrentar condições fisiopatológicas mediadas por espécies reativas de oxigênio (AZUMA et al., 2014)

A ozonioterapia tem sido extensivamente estudada nas últimas décadas e utilizada na medicina há mais de 150 anos em vários países, com eficácia comprovada, consistente e mínimos efeitos adversos, para tratamento de mais de 114 patologias (ELVIS; EKTA, 2011). Apesar disso, essa técnica não é muito utilizada nem tem seus benefícios defendidos pelos médicos no Brasil, sendo liberada para ser usada apenas com caráter experimental, segundo o Conselho Federal de Medicina (BRASIL, 2018).

A habilidade do ozônio para desinfecção de água foi descoberta em 1886 e em 1891, onde testes pilotos já eram realizados em Martinkenfelde, na Alemanha. No entanto, a primeira instalação de ozônio em escala industrial ocorreu em 1893, em Oudshoorm, na Holanda, objetivando a desinfecção de água na estação de tratamento de água potável 
desta cidade. Passou a ser utilizado comercialmente em 1903 para tratamento de água potável (SOUZA, 2016b).

Lopes, Oliveira e Serra (2013) sustentam que o ozônio, quando aplicado na água, age como potentíssimo oxidante de contaminantes, produzindo moléculas inócuas precipitadas, gerando oxigênio como subproduto, tais autores asseguram ainda:

A ação do Ozônio é extremamente rápida ( $<1 / 10$ s) e não-seletiva (mata todos os micro-organismos: bactérias, fungos, bolores, vírus, etc.). Para os autores o ozônio possui características como a redução de metais à suas formas insolúveis (normalização), destruição de hidrocarbonetos por dissociação (quebra das cadeias), Solidificação (mineralização) de compostos orgânicos dissolvidos causando a sua coagulação e precipitação, elevação do potencial redox da água, causando microfloculação (microprecipitação) dos patogênicos e pirógenos destruídos, que podem facilmente ser removidos por filtração, além de não permitir a formação de residual remanescente na água devido o tempo de reação ser reduzido (LOPES; OLIVEIRA; SERRA, 2013, p.23-26,).

Silva e seus colaboradores (2011), afirmam que o ozônio pode ter ainda outras utilizações, como em purificadores de água domésticos e para a higienização de hortaliças. Tem-se ainda a possibilidade de uso na sanitização de processos e produtos na indústria de alimentos, por ser a contaminação um dos principais problemas dentro da indústria e pelo fato de ozônio ser uma alternativa barata e segura para o consumidor.

$\mathrm{Na}$ odontologia contemporânea, também tem se falado muito na utilização do ozônio por se tratar de um meio de esterilização eficaz e rápido. O ozônio que, pelo seu amplo espectro de ação antimicrobiano e ainda por atuar como agente "purificador" da água, pode auxiliar o processo de descontaminação do sistema de distribuição de água dos consultórios dentais, além de poder ser utilizado na esterilização ou desinfecção de materiais e instrumentos utilizados nessa área, levando a um padrão aceitável de sua qualidade (NOGALES et al., 2008).
Quanto ao óleo ozonizado, foi criado por médicos alemães no ano de $1905 \mathrm{com}$ a finalidade de obter formulações de derivados de ozônio que possuíssem boa estabilidade para facilitar a manipulação do ozônio gasoso, melhorar seu armazenamento, evitar sua rápida degradação, permitir um tratamento extra-hospitalar e diminuir o risco de usá-lo na forma gasosa, em doses altas e inadequadas (SADOWSKA et al., 2008). O ozônio reage com as ligações duplas dos ácidos graxos presentes nos óleos vegetais formando, em especial, os ozonídeos (anéis 1,2,4-trioxolanos) e espécies peroxídicas como hidroperóxidos, peróxidos de hidrogênio, peróxidos poliméricos e outros peróxidos orgânicos.

Sua fabricação solidificada necessita de dois dias de gás ozônio borbulhado continuamente em óleo vegetal, fazendo com que um grama do óleo contenha 160mg de ozônio. Quando refrigerado possui validade de dois anos. O óleo ozonizado também pode ser fabricado em menos tempo, ficando mais viscoso e com menor duração (BOCCl et.al, 2005).

\section{MATERIAIS E MÉTODOS}

Trata-se de uma pesquisa exploratória com abordagem quali-quantitativa, realizada por meio da aplicação de gás e óleo ozonizado a microrganismos, testando, assim, a sensibilidade deles ao ozônio e comparando sua ação em diferentes veículos.

Foram selecionados três microrganismos comuns em infecções hospitalares, cujas colônias padrão em estudo foram cedidas pela Universidade Federal de Uberlândia. São elas: Staphylococcus aureus ATCC 25923, Escherichia coli ATCC 25922 (American Type Culture Collection), e uma cepa de Staphylococcus aureus resistente à meticilina (MRSA).

O gás ozônio foi obtido através de gerador fabricado pela Ozone \& Life, modelo O\&L 1.5 RM, utilizando cilindro de oxigênio medicinal, cujo gás foi convertido em $\mathrm{O}_{3}$ na proporção máxima de $3 \% \mathrm{em}$ mistura $\mathrm{O}_{2} / \mathrm{O}_{3}$, através do princípio de descargas em barreira dielétrica. A mistura gasosa utilizada atingiu concentração de aproximadamente $72 \mu \mathrm{g} / \mathrm{ml}$ de Ozônio, de acordo com dados fornecidos pelo fabricante do gerador.

Para o teste com o gás, foram feitas replicações das colônias em placa de Petri, utilizando meio de 
um período de 12 horas. Após esse processo, os papéis foram inoculados nas placas, sendo as mesmas incubadas em estufa a $35 \pm 2$ o também por 24 horas. Após o tempo de incubação, foi verificada a formação de halos em volta dos discos de papel, que foram mensurados com régua, para determinar, assim, a sensibilidade ou resistência do microrganismo à substância em estudo.

\section{4}

\section{RESULTADOS E DISCUSSÃO}

A formação do ozônio no gerador consiste na administração de uma corrente elétrica no fluxo de oxigênio proveniente do cilindro com o gás medicinal. O campo elétrico proporciona energia necessária para que as duplas ligações da molécula de oxigênio se rompam, formando dois átomos de Oxigênio radicalar. Dessa forma, esses átomos reagem com outras moléculas de $\mathrm{O}_{2}$, dando origem às moléculas de $\mathrm{O}_{3}$ (LAPPOLI et al., 2005).

Segundo autor supracitado, a capacidade de antissepsia do ozônio, sobre todos os tipos de microrganismos, inclusive em cistos e formas esporuladas, é aproximadamente dez vezes maior que a do cloro. No presente estudo observamos uma significativa atuação in vitro do ozônio sobre os microrganismos selecionados.

No teste feito com o gás, os microrganismos cultivados nas placas não conseguiram se desenvolver após a exposição do gás ozonizado em aproximadamente $72 \mu \mathrm{g} / \mathrm{ml}$ sobre elas durante o tempo total de 40 minutos. Nas placas de $S$. aureus houve um leve crescimento no início do estriamento da placa causado, provavelmente, por esta parte ter a primeira passagem do swab, tendo uma maior concentração de bactérias, como notamos nas Figuras 4, 5 e 6.

Tais resultados são condizentes com Sheldon e Brown (1986), os quais afirmam que o ozônio é capaz de proporcionar uma redução de $78 \%$ de microrganismos aeróbios, 91\% de coliformes, quando contraposto ao método de sanitização com cloro ativo.

Harris (1972) afirmou, no início dos estudos com ozônio, que o gás ozonizado exigiria um tempo de contato de cinco a dez minutos com o objeto a ser esterilizado para um resultado rápido e eficaz. Contudo, levando fatores em consideração como a área a ser descontaminada e a concentração de microrganismos dispostas no meio, torna-se explicito que o tempo de exposição ao gás deve ser maior.

Figura 4 - Resultado para S. aureus: Demonstra diferença ente as placas contendo $S$. aureus, placa A é o grupo controle e a Placa B foi exposta diretamente sobre o gás ozonizado, obtendo-se um excelente resultado de inibição do crescimento bacteriano

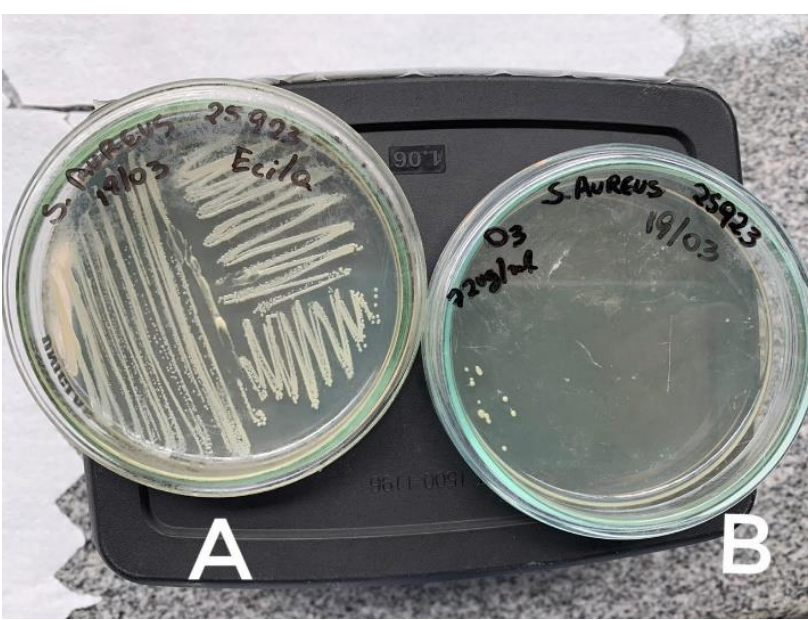

Fonte: os autores

Figura 5 - Resultado para S. aureus MRSA: Conclui-se excelente resultado na inibição do crescimento bacteriano, placa $A$ foi exposta diretamente sob gás ozônio e placa B é nosso grupo controle.

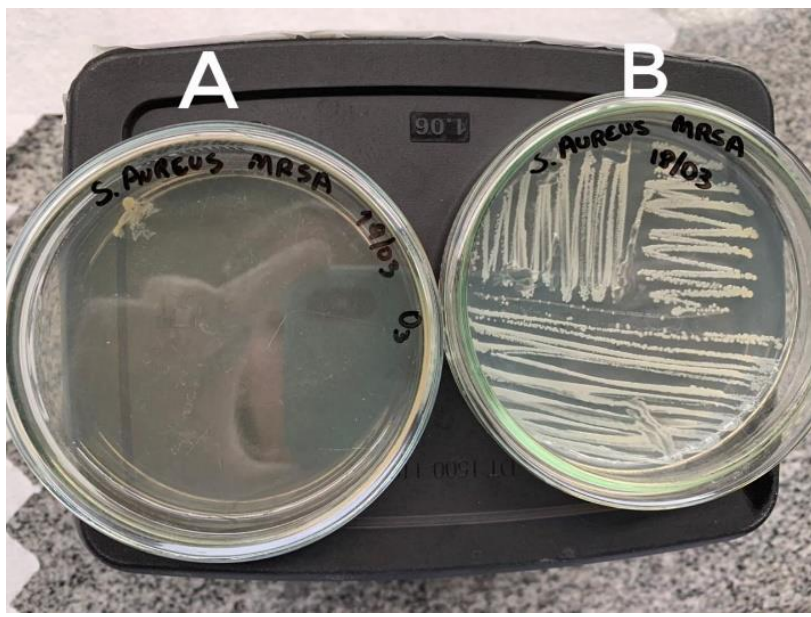

Fonte: os autores.

Quanto ao teste de sensibilidade com o óleo ozonizado, observou-se formação de halo de inibição ao redor do papel filtro em todas as cepas testadas, o que indica sensibilidade dos microrganismos ao ozônio. O teste de disco-difusão tem como princípio a presença ou ausência de 
Figura 9 - Resultado do óleo ozonizado para E. coli: Após 24 horas de incubação, obteve-se formação de um halo de $1 \mathrm{~cm}$.

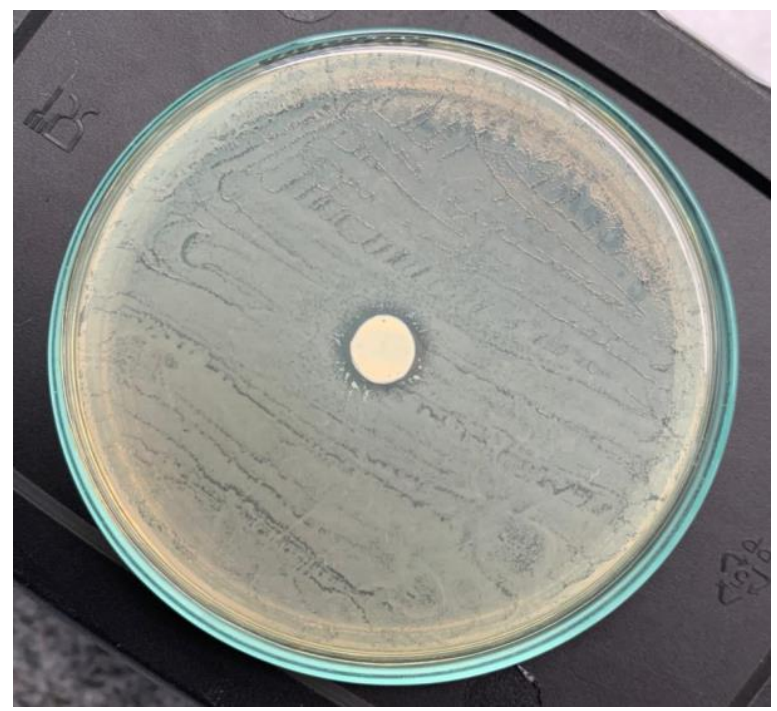

Fonte: os autores.

\section{CONCLUSÃO}

O ozônio é um poderoso agente antimicrobiano com um grande potencial de uso para fins de desinfecção, sendo de grande utilidade na antissepsia de ambientes hospitalares e EPI. Desse modo, quando comparado ao cloro, o ozônio apresenta-se mais efetivo, sendo um vigoroso desinfetante que se decompõe aceleradamente e não gera subprodutos tóxicos. Além disso, quando obtido o equipamento, a geração do ozônio é de baixo custo se comparado com a compra periódica feita para os demais sanitizantes.

Por meio do teste realizado, ficou evidenciada ação positiva do ozônio gasoso na contenção do crescimento bacteriano, podendo ser extremamente promissor o seu uso em diversos fins. Referente ao óleo, o teste demonstrou sensibilidade dos microrganismos frente ao ozônio, porém, fica evidente a necessidade de outros estudos, com utilização de metodologia mais complexa, para melhores resultados.

Portanto, mesmo com algumas restrições, foi confirmada a capacidade do gás e do óleo ozonizado de conter e combater $o$ crescimento de microrganismos, sendo o ozônio em sua forma gasosa mais potente para fins de descontaminação.

\section{REFERÊNCIAS}

AZUMA, K.et.al. Anti-inflammatory effects of ozonated water in na experimental mouse model. Biomedical Reports, v.2, n.5, p.671-674, set.2014. Disponível em: http://www.spandidospublications.com.br/2/5/671?text=fulltext. Acesso em: 19 out.2019

BRASIL. Conselho Federal de Medicina. Resolução 2.181, de 20 de abril de 2018. Ozonioterapia como procedimento experimental, só podendo ser utilizada em experimentação clínica dentro dos protocolos do sistema CEP/Conep. Diário Oficial da União, Brasília, DF, 10jul. 2018. p.106. Disponível em: http://www.portal.cfmv.gov.br/lei/downloadarquivo/id/1096. Acesso em: 03 dez. 2019.

BOCCHI, L. et al. Oxygen-ozone in orthopaedics: EPR detection of hydroxyl free radicals in ozonetreated "nucleus pulposus" material. Riv

Neuroradiol. p. 55-9, 2005.

CAVALCANTE, D.A. Avaliação da eficiência da aplicação do ozônio na cadeia de produção do queijo minas frescal p.33. Tese (doutorado) Universidade Estadual de Campinas, Campinas, SP, 2012. Disponível em:

http://repositorio.unicamp.br/handle/REPOSIP/254 828. Acesso em: 19 out. 2019.

DÍAZ, S. et al. No increase in sister chromat idex changes and micronuclei frequencies in humanlym phocytes exposed to ozone in vitro. Proceedings Ozone in Medicine 12th World Congress of the International Ozone Association, 15th to 18th May, Lille France.1995.

DENNIS, A. N. COVID-19, Key Questions for Impact Analysis: A Worldwide Pandemic. Journal of Surgery Current Trends \& Innovations, California, United States, 2020.

ELVIS, A.; EKTA, J. Ozone therapy: A clinical review. Journal of Natural Science, Biology and Medicine, v. 2, n. 1, p. 66, jan. 2011.

FARIAS, JBF et al. Ozonioterapia como adjuvante no tratamento da COVID-19. Rev Bras Fisiol Exerc 2020. Disponível em:

https://doi.org/10.33233/rbfe.v19i2.4116. Acesso em: 03 mai. 2020. 
FERRACIOLI J. et al. Bactéria Staphylococcus aureus. In: Congresso Multidisciplinar. 2019. Disponível em: http://www.fap.com.br/anais/congressomultidisciplinar-2019/poster/183.pdf. Acesso em maio 2020.

FISHER, A. et al. Correlação funcional em mutações de resíduos de aminoácidos do iso-2-citocromo c de levedura que é consistente com a previsão da teoria do códon concomitantemente variável na evolução do citocromo c. Bioquímica genética, $v$. 38, n. 5-6, p. 177-196, 2000.

GIMENES, C. Aplicações do ozônio. Diário do Nordeste, Fortaleza, 08/06/2008. Disponível em: http://diariodonordeste.globo.com/materia.asp?co digo=543761 Acesso em: 04 nov. 2019.

GURLEY, B., Ozone: pharmaceutical sterililant of the future? Journal of Parenteral Science and Tecnology, v. 39, n.6, p. 256-261, 1985.

HARRIS, W. C. Ozone disinfection. Journal American Water Works Association, v. 64, n. 3, p. 182-183. 1972.

KIM, J.G. et al. Application of ozone for enhancing the microbiological safety and quality of foods: a review. Journal of food protection, v. 62, n. 9, p. 1071-1087, 1999.

LAPOLLI, F. R. et al. Desinfecção de efluentes sanitários através de dióxido de cloro. Engenharia Sanitária e Ambiental, v. 10, n. 3, p. 200-208, 2005.

LEÓN, O. S. et al. Ozone oxidative preconditioning: a protection against cellular damage by free radicals. Mediators of Inflammation, v. 7, n. 4, p. 289-294, 1998.

LOPES R. R. et al. Avaliação comparativa entre os métodos de desinfecção empregando cloro e ozônio de águas destinadas ao abastecimento de pequenas comunidades. Periódico Eletrônico Fórum Ambiental da Alta Paulista, v. 9, n. 11, p. 23-26, 10 nov. 2013.

LUONGO M. et al. Advanced dressings and oxygenozone therapy to treat ulcers in chronic obliterant peripheral artheriopathies (AOCP). Eur J Clin Invest. 2003.
NOGALES, C. G. et al. Avaliação da ação da água ozonizada frente a bactérias encontradas em casos de periodontite apical secundária persistente. Braz Oral Res, p. 23-188, 2008.

RICE, R. G. et al. Uses of ozone in drinkingwatertreatment. Journal of the American Water Works Association, Denver, v. 73, n. 1, p. 44-47, 1981.

OLIVEIRA, J.O.J. Fisiologia da ozonioterapia. Apostila do curso de ozonioterapia, março de 2008.

PEREIRA, M. M. et al. Efeito de diferentes gases sobre o crescimento bacteriano: estudo experimental" in vitro". RevColBrasCir, v. 32, n. 1, p. 12-14, 2005.

RENSI, A.M; et.al Avaliação do efeito de óleos ozonizados de girassol e coco no controle propeonibacteriumacnes, XXIV. Congresso brasileiro de engenharia Biomédica. São Jose dos Campos. 2014.

SADOWSKA J. et al. Characterization of ozonated vegetable oils by spectroscopic and chromatographic methods. Chemistry and Physics of Lipids. 2008; 151:85-91. DOI: 10.1016/j.chemphyslip.2007. 10.004

SANTOS, André Luis dos et al. Staphylococcus aureus: visitando uma cepa de importância hospitalar. In: J. Bras. Patol. Med. Lab., Rio de Janeiro, v. 43, n. 6, dez. 2007. Disponível em: http://www.scielo.br/scielo.php?script=sci arttext \&pid=S167624442007000600005\&lng=en\&nrm=iso . Acesso em: maio 2020.

SECHI L.A, et al. Antibacterial activity of ozonized sunflower oil (Oleozon). J Appl Microbio, p.279-84, 2001.

SHELDON, B.W.; BROWN, A.L. Efficacy of ozone as a desinfectant for poultry carcasses and chillwater. Journal of Food Science, v.51, n.2, p. 305-309, 1986.

SILVA, S.B.; LUVIELMO, M.M.; GEYER, M.C. \& PRÁ, I. Potencialidades do uso do ozônio no processamento de alimentos. Ciências Agrárias, Londrina, v.32, n.2, p.659-682, 2011. 
SOUZA, C. O. et al. Escherichia coli enteropatogênica: uma categoria diarreiogênica versátil. In: Rev Pan-Amaz Saude, Ananindeua, v. 7, n. 2, jun. 2016a. Disponível em:

http://scielo.iec.gov.br/scielo.php?script=sci arttex t\&pid=S217662232016000200079\&lng=pt\&nrm=is o. Acesso em: maio 2020.

SOUZA, S.M.O. Estudo da interferência de substratos orgânicos na ação do ozônio sobre microrganismos deteriorantes, benéficos e patogênicos. 2016b. Tese (Doutorado em Ciência Animal) - Universidade de Brasília, Brasília, 2016.

WENTWORTH, P. Evidence for Antibody-Catalyzed Ozone Formation in Bacterial Killing and Inflammation. Science, v. 298, n. 5601, p. 21952199, 13 dez. 2002. 